\title{
The Effects of Video Feedback with Verbal Cues on Performance of Basketball Free Throw Shooting by Female Junior Basketball Beginners 錄像配合口頭回䫀對初中女子籃球初學者罰球表現的影響
}

\author{
Kwok Mun LUK \\ Christian and Missionary Alliance \\ Sun Kei Secondary School, HONG KONG
}

Alberto CRUZ Violette Fu Po LIN
Department of Creative Arts and Physical Education
The Hong Kong Institute of Education, HONG KONG

陸幗敏

香港基督教宣道會宣基中學

高薘倫＼cjkstart林伏波

香港教育學院體藝學系

\begin{abstract}
This study was to investigate whether with the aid of verbal cues, video modeling with verbal cues and self-video replay with verbal cues were effective in enhancing the free throw ability for female junior basketball beginners. Participants were 24 female learners aged 13 to 14 years with no or little experience in free throw shooting. With equal ability among groups, they were divided into four equal groups (n=6), (1) control group (CG), (2) verbal feedback group (VG), (3) verbal cues with videotaped modeling (VMG), and (4) verbal cues with video replay (VRG). After an observation of a video clip with successful shooting attempts by an expert player, all participants were given two days of acquisition sessions with 120 trials in total and a retention test one day after the practice sessions. Both scoring accuracy and shooting form were evaluated, and a two-way analysis of variance ANOVA (4 groups X 3 trials) with repeated measures on the trial factor was used to analyze the effects of four different feedback methods for two basketball skill performance. It was found that with the aid of verbal cues, both video modeling and self-video replay were effective in enhancing the basketball free throw form in female basketball beginners.
\end{abstract}

\section{摘 要}

本研究旨在探討配合口頭回饋、示範錄像及自我重放錄像能否有效提升初中女籃球初學者之射罰球能力。24個參加者為中二 級女生，他們被分成4個相等能力組別 $(\mathrm{n}=6)$ ：(1) 對照組 $(\mathrm{GG})$ 、(2) 口頭回饋 $(\mathrm{VG})$ 組、(3) 示範錄像及口頭回饋 $(\mathrm{VMG}) 、(4)$ 自 我重放錄像及口頭回饋 $(V R G) 。$ 評估內容包括投射準確度和動作技巧, 並使用雙因素方差ANOVA分析不同的實驗組的表現。研究 結果顯示，配合口頭回瞶、示範錄像及自我重放錄像均能有效提升初中女籃球初學者之射罰球能力。 


\section{Introduction}

Providing accurate and useful feedback is essential in motor learning as the feedback helps both the teacher and the learner evaluate the correctness of performance and an incentive to motivate the learner in the skill acquisition process (Rose \& Christina, 2006). Various feedback strategies have been researched in different movement programmes and athletics settings for improving learners' quality or efficiency in a variety of skills. These strategies include verbal cues, video modeling and self-video replaying (A1-Abood, Davids, \& Bennett, 2001; Anshel \& Singer, 1980; Janelle, Champenoy, Coombes, \& Mousseau, 2003; Singer, Flora, \& Abourezk, 1989; Tzetzis, Mantis, Zachopoulou, \& Kioumourtzoglou, 1999).

Verbal cueing is commonly used in motor learning. According to Landin (1994), verbal cues are concise phrases, often just one or two words that either direct a learner's attention to relevant task stimuli or prompt the learner the key movement pattern elements of a motor skill. These cues can be provided during preliminary instructions and feedback. Since concise phrases convey the critical elements of a skill or movement to the learner, he/she is stimulated to focus on key elements of movement, thus facilitating his/her acquisition of the motor skill (Parson, 1998). Furthermore, as the learner is informed about what technical errors are presented and how to correct those errors, it can narrow the gap between the learner's actual performance and the correct technique. However, in many situations, verbal cueing alone is insufficient, especially when a skill is relatively complex (Wiese-Bjornstal \& Weiss, 1992). In such case, the learner will need visual cues such as live demonstrations by the coach.

With a tremendous development of the video-taking technology in recent years, coaches can pre-record the desired motor skills as a video and use it as a teaching aid to improve learners' performance (Darden \& Shirmon, 2000; Pollock \& Lee, 1992). With this teaching aid, video modeling is developed. It is a practice procedure that a learner attempts to reproduce a desired behaviour demonstrated in the form of video by other individual, usually an expert of that skill (Schmidt \& Wrisberg, 2008). Video modeling is particularly useful for skills with relatively complex spatiotemporal demands, such as basketball free throw shooting. It enables the learner to understand the task requirements of normally high speed movements at a slower speed. This unique feature allows the learner to capture some elements lost at realtime observation in live demonstration and then the coach can focus on providing verbal cues to facilitate learning the skill.

Besides featuring an expert's performance, the video can also record the learner's performance and provide feedback for improvement. Self-video replaying is a process that allows a learner to view and critique his/her own movement form through watching the video playback (Janelle, Barba, Frehlich, Tennant \& Cauraugh, 1997). The learner first executes the skill; the performance is then recorded onto a storage component via a camera and then being viewed as video images. At the viewing process, the learner is exposed to the precision, execution and amplitude of his/her technique.

Despite the benefits of using these feedback strategies in teaching and learning motor skills, there is limited research on the combinations of using verbal cues and videoing in basketball shooting and the findings on their effectiveness in other skills are contradictory (Martens, Burwitz, \& Zuckerman, 1976; Morrison \& Reeve, 1988; Pettay \& Dzewaltowski, 2001; Thomas, 1998). Moreover, it is uncertain if such research findings are applicable to Hong Kong learners. Therefore, the purpose of this study was to investigate the effects of three different feedback strategies on the acquisition and retention of two basketball skills as compared with a control group, for female basketball learners of 13-14 years old with no or little experience in free throw shooting.

\section{Methodology}

\section{Participants}

Twenty four female basketball players studied in Form Two at a local mainstream secondary co-education school were recruited to participate in the study. They aged from 13 to 14 years $(13.2 \pm 0.38$; mean \pm standard deviation, SD), with no or little experience of singlehand free throw basketball shooting. They were all righthanded with normal or corrected-to-normal vision. All participants gave informed consent prior to participation. 


\section{Procedures}

At the pre-test, all participants were evaluated for free throw shooting ability with 20 trials. They were randomly assigned to one of the four experimental groups, with the constraint that they were of roughly equal free throw shooting ability: (1) control group (CG), (2) verbal feedback group (VG), (3) verbal cues with videotaped modeling (VMG), and (4) verbal cues with video replay (VRG).

After that, the participants watched a video of a highly skilled player performing successful free throw shooting with six repetitions; they were reminded to focus on the model's shooting form. Then, they underwent two parts held on different days: acquisition and retention. The acquisition was done on two days. On the first acquisition day, after viewing the video, the participants completed the first practice session. It consisted of 60 trials which were divided into 3 blocks with 20 trials per block separated by a 10-minute rest each. The second acquisition day was completed identically as the first day. The day after the two practice sessions, participants were prohibited from practice. One day later, they were given a no-feedback retention test. This resulted in completing 120 practice shootings and 20 trials in retention test.

All participants followed the same experimental procedures but differed with respect to whether they received verbal instructions, video aids or neither. The participants in the CG were not exposed to either form of instructional constraints, while the VG was given verbal cues concerning about the most critical error made during the block of shootings. The VMG observed a video modeling after every block throughout acquisition part with given verbal cues as well. For the VRG participants, besides providing verbal cues, they were given their own video replay between blocks during the practice session. They were asked to use the corresponding feedback that they received to help them to improve their performance. The time spent with each participant by the first author as the instructor was kept relatively constant and the numbers of verbal cues were limited to less than three. All participants were tested individually by the first author and trained helpers.

\section{Data Measures}

Shooting form was assessed based on the following criteria: (1) feet were shoulder-width apart, with right foot slightly in front of left foot and knees bent; (2) the shooting elbow was kept in and under the basketball, and pointed at the basket upon release; (3) the shooting arm and both legs were fully extended during the throwing motion; and (4) when the ball was released, the right wrist was snapped down, with all fingers pointing between the basket and the floor. This position was held until the ball reached the basket. For each of the four criteria, participants received either a score of 2 (clearly recognisable), 1 (vaguely recognisable), or 0 (not recognisable). Thus, the total score ranged from 0 to 8, with the highest indicating perfect performance. Components of correct form were identified as those most consistently mentioned as essential for accurate shooting in a number of basketball training manuals (Amberry, 1996; Barney \& McGaha, 2006; Hagedorn, Niedlich, \& Schmidt, 1996) and emphasized in the video demonstration clip.

Shooting accuracy was measured as follows: (1) 5 points for a ball went through the basket; (2) 3 points for a ball touched the ring; (3) 2 points for a ball touched both the board and the ring; (4) 1 point for a ball touched the board only; and (5) 0 point for a ball touched neither the basket nor the board. This strict scoring method was used to eliminate the effects of the backboard on shooting performance and to clarify the relation between proper form and shooting performance (Wulf, Raupach \& Pfeiffer, 2005).

Data were collected for both practice and retention tests. For practical reason, the shooting form and accuracy analyzed only the first, the fifth, the tenth, the fifteenth and the last acquisition trials for each block and all the trials in the retention test were analyzed for examining the effects of different conditions in shooting. The mean data of the two acquisition trials were used to represent the practice scores.

\section{Data Analysis}

Group means and standard deviations were calculated for pretest, practice session and retention. One-way ANVOA was used to analyze the initial differences of the pretest scores for the four groups both in scoring accuracy and shooting form. Two-way ANOVA (4 groups $\mathrm{X} 3$ trials) with repeated measures on the trial factor was 
used to determine the main and interactions effects of the different feedback methods on the scores of basketball form and accuracy. A post hoc Tukey test was used to analyze the differences of the means whenever an overall significance difference was found. Statistical significance was set at .05 level. The Statistical Package for Sciences (SPSS) version 15.0 was used to complete the statistical analysis.

\section{Results and Discussion}

\section{(1) Scoring accuracy}

At pre-test, one way ANOVA did not reveal any significant difference $\left(\mathrm{F}_{3,20}=0.115, \mathrm{p}=.951\right)$ in scoring accuracy among the four groups (see Figure 1).

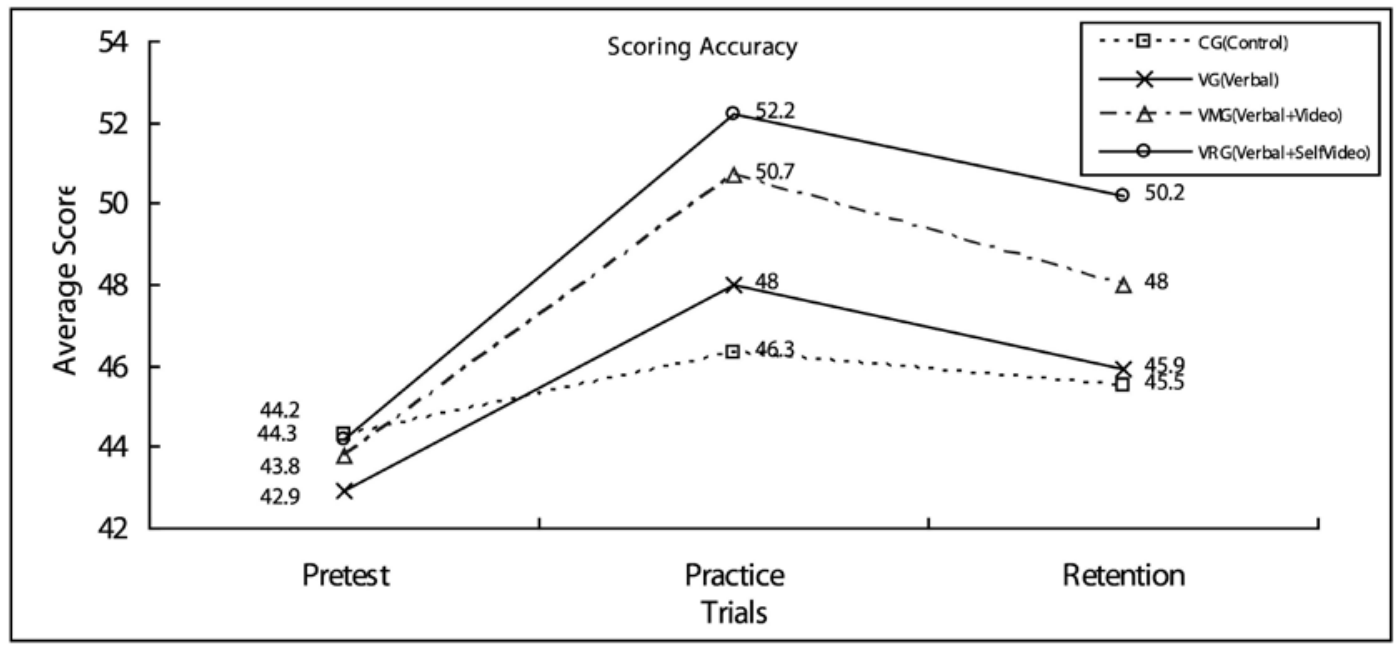

Figure 1. The group means and SD for the scoring accuracy for the pretest, practice session and retention of the four groups $(n=6)$.

There was no significant interaction $\left(\mathrm{F}_{6,60}=0.736\right.$, $\mathrm{p}=.592$ ) for the different trials and the groups for the scoring accuracy. The main Group effect among the four groups was not significantly different $\left(\mathrm{F}_{3,60}=2.500, \mathrm{p}=.068\right)$, but the main Trial effect was significantly different $\left(\mathrm{F}_{2,00}=9.326\right.$, $\mathrm{p}=.000)$.

Among all groups, the changes in scores followed a similar pattern: an increase of scores at the Practice stage and a decrease at the Retention stage.
For CG, there was no significant $\left(\mathrm{F}_{2,15}=0.465\right.$, $\mathrm{p}=$.637) main effect among the three trials. There was also no significant $\left(\mathrm{F}_{2,15}=1.325, \mathrm{p}=.295\right)$ main effect among the three trials for VG. However, the main Trial effect was significant in VMG $\left(\mathrm{F}_{2,15}=4.267, \mathrm{p}=.034\right)$ and $\mathrm{VRG}\left(\mathrm{F}_{2,15}=5.015\right.$, $\mathrm{p}=.021)$. For $\mathrm{VMG}$, the Tukey post-hoc analysis revealed that the mean scores at practice was 6.9 (95\% CI 0.72-13.1) greater than that at pretest. For VRG, the Tukey posthoc analysis revealed that the mean scores at practice was 7.9 (95\% CI 1.17-14.7) greater than that at pretest. There was no significant difference between the pretest and the retention test scores for both groups. 


\section{(2) Shooting form}

Figure 2 shows the group means and SD for the shooting form performance for the pretest, practice session and retention of the four groups $(n=6)$ (see Figure 2). The total score ranged from 0 to 8 , with the highest indicating perfect performance.

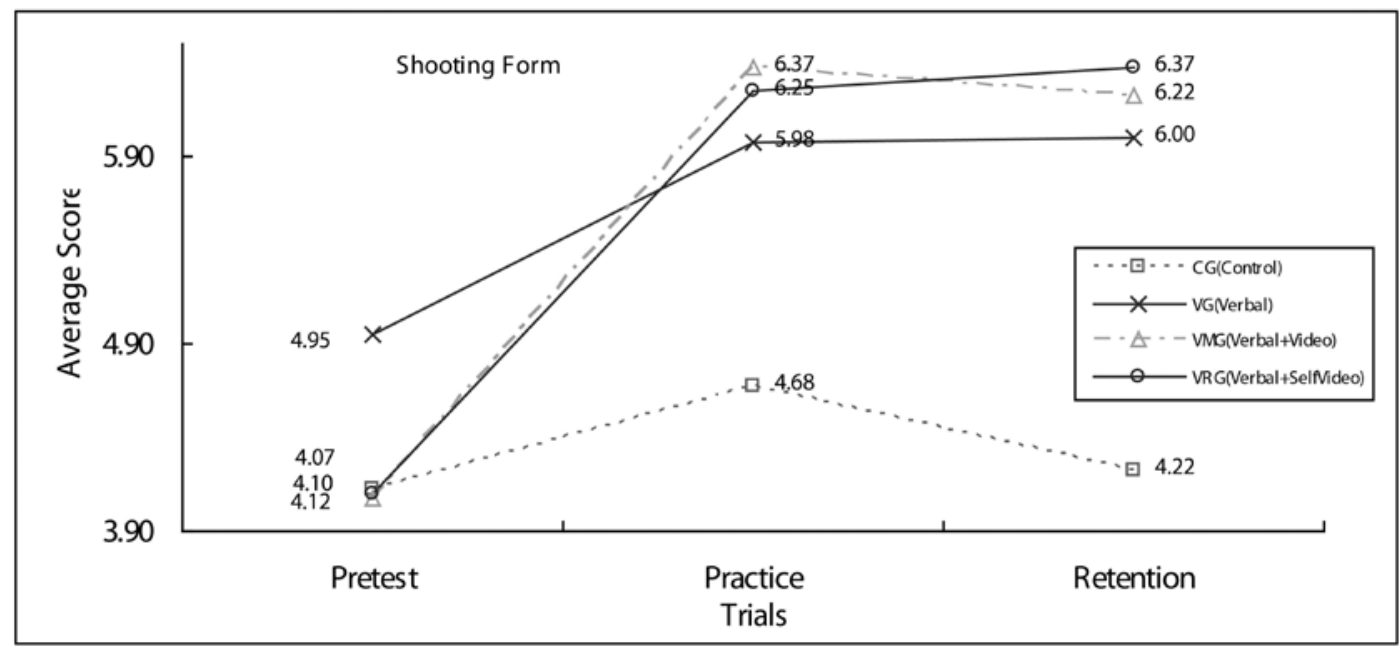

Figure 2. The group means and SD for the shooting form for the pretest, practice session and retention of the four groups $(n=6)$.

There was a significant interaction $\left(\mathrm{F}_{6,60}=4.748\right.$, $\mathrm{p}=.001$ ) for the different trials and the groups for the shooting form performance. The main Group effect among the four groups was significantly $\left(\mathrm{F}_{3,60}=18.359\right.$, $\mathrm{p}=.000)$, and so was the main Trial effect $\left(\mathrm{F}_{2,60}=43.829\right.$, $\mathrm{p}=.000$ ) among the three trials.

At pre-test, one-way ANOVA did not reveal any significant difference $\left(\mathrm{F}_{3,20}=2.211, \mathrm{p}=.118\right)$ in shooting form performance among the four groups. At practice, there was a significant $\left(\mathrm{F}_{3,20}=14.635, \mathrm{p}=.000\right)$ main effect among the four groups. The Tukey post-hoc analysis revealed that the mean score for $\mathrm{CG}$ was significantly lower than VG (by 1.3, 95\% CI 0.49-2.11), VMG (by 1.7, 95\% CI 0.89-2.50), and VRG (by 1.6, 95\% CI 0.77 2.38). The three groups were not significantly different. At retention, there was also a significant $\left(F_{3,20}=14.624\right.$, $\mathrm{p}=.000$ ) main effect among the four groups. The Tukey post-hoc analysis revealed that the mean score for CG was significantly lower than VG (by 1.8 , 95\% CI 0.75 2.82), VMG (by 2.0, 95\% CI 0.97-3.04), and VRG (by 2.2, 95\% CI 1.12-3.19). The three groups were not significantly different.
For CG, there was no significant $\left(\mathrm{F}_{2,15}=1.579\right.$, $\mathrm{p}=.239)$ main effect among the three trials. There was also no significant $\left(\mathrm{F}_{2,15}=2.999, \mathrm{p}=.080\right)$ main effect among the three trials for VG. However, the main Trial effect was significant in VMG $\left(\mathrm{F}_{2,15}=35.737, \mathrm{p}=.000\right)$ and VRG $\left(\mathrm{F}_{2,15}=46.641, \mathrm{p}=.000\right)$. For $\mathrm{VMG}$, the Tukey post-hoc analysis revealed that the mean scores at practice was 2.3 (95\% CI 1.51-3.10) higher than that at pretest; that at retention was 2.2 (95\% CI 1.36-2.94) higher than that at pretest. For VRG, the Tukey post-hoc analysis revealed that the mean scores at practice was 2.2 (95\% CI 1.46-2.84) higher than that at pretest; that at retention was $2.3(95 \%$ CI 1.58-2.95) higher than that at pretest; that at practice and at retention was similar. There was no significant difference between the practice and the retention test scores for both groups.

\section{Discussion}

The study design was carefully planned to ensure that the differences in performance in the groups were due to the various feedback strategies. This was done by evenly and randomly assigning the participants into the four groups after the pre-test as revealed in the pre-test one-way ANOVA statistics. 
For scoring accuracy, all groups seemed to have an improvement in performance at the practice trial (Figure 1), however the change might be a test-retest effect as CG also had such improvement. Nevertheless, these improvements could not retain in the learners.

There was no main Group effect, which indicated that the different feedback modalities were effective in enhancing free-shooting accuracy. However, the significant Trial main effect and the Tukey post-hoc analysis revealed that in both VMG and VRG, the practice scores were 6.9 (95\% CI 0.72-13.1) and 7.9 (95\% CI 1.17-14.7), respectively greater than that at pretest. This implies the use of video, either through modeling the expert or through self-criticism; free-shooting accuracy has improved, at least immediately during the practice session.

It is uncertain why such positive effective could not retain after one day in the retention test, it might due to the novelty of the free-hand shooting skill for the participants. From the visual perception perspective (Newell, Morris \& Scully, 1985), differences in movement outcome because of modeling would be observed if the goal of the task requires the assembly of a new or unfamiliar pattern of movement coordination. In the present study, we observed from the first practice trial that most participants were able to generate relative motions similar to that demonstrated by the model, which implies that the single-handed shooting skill might actually be not novel to them. Therefore, it is suggested that there were no significant modeling advantages for movement outcomes because of the novelty of the task.

Besides novelty of skill, the non-significant differences among the four groups may also be a result of the conservative Tukey post-hoc test. In VRG, with the help of video replay and verbal cues, the participants performed the best among the four groups. Other studies have also demonstrated self-videoing an effective feedback strategy in learning various motor skills (Onate, Guskiewicz, Marshall, Giuliani, Yu, \& Garrett, 2005; Tzetzis, Mantis, Zaxhopoulou \& Kioumourtzoglou, 1999). It is probably because the self-video clip enables the participants to remember their successful attempts movement forms that enhance their shooting accuracy.

In the present study, the contents of the selfvideo clips were not limited in which the subjects could be affected by the successful attempts or unsuccessful attempts. Perhaps video replay helps in another way that the learners notice own errors from unsuccessful attempts, thus producing a more refined shooting movement form that lead to enhance outcome scores. Magill (1993) supported that a combination of errorbased augmented feedback and information based on what was done correctly is the most useful. In the present study, self-video replay provided both successful attempts and unsuccessful attempts may act as a combination of augmented feedback which takes the advantageous roles of augmented feedback for motivating a person to continue practicing the skill and facilitating skill improvement.

From the above findings, it is concluded that verbal cues solely might not be an effective feedback strategy in improving single-handed shooting accuracy. However, combining with video modeling or self-video replay, verbal cues enhance the scoring accuracy immediately during practice, but the skills have not been retained. In future research, increasing the duration of practice session may help to improve the retention ability of a skill (Swinnen, 1998).

The participants' performance in single-handed shooting form is another criterion to evaluate the effectiveness of the different feedback strategies. Figure 2 shows that besides the CG, all groups demonstrated improvements in shooting form across practice as revealed in the significant interaction $\left(\mathrm{F}_{6,60}=4.748, \mathrm{p}=.001\right)$ for the three trials and the four groups, the main Group effect $\left(\mathrm{F}_{3,60}=18.359, \mathrm{p}=.000\right)$, and the main Trial effect $\left(\mathrm{F}_{2,60}=43.829\right.$, $\mathrm{p}=.000$ ) for the shooting form performance.

From the analysis of the main Trial effect and its Tukey post-hoc tests, it is revealed that excepted for CG, all feedback methods enhanced shooting form both during practice and at the retention test with an average of 1 to 2 points out of the 8-point scale. The effects were similar for the three modes. Janelle and co-workers (2003) also found an improvement in soccer accuracy pass tests in observational learning. Surprisingly, both video modeling and self-video replay had similar effects as verbal cueing. With an additional cue (visual) added, the shooting form should improve more than that by verbal cueing per se. This finding diverts from some studies which found that experts' modeling is of no use in assisting learning, to the contrary it will interfere learning (Schmidt \& Wrisberg, 2008) and video replay may be redundant and unnecessary (Kernodle et al., 
2001). It might be because the single-handed shooting form was not complicated to the participants, thus the use of verbal cues has already provided sufficient information for the participants to retain the movement form of free throw shooting. Probably, the verbal cues in the present study presented as an acronym was effective in helping the participants to remember one's critical criteria when evaluating shooting form. The concise phrases may have already been memorised by the participants in the early stage of the study.

From the above findings, it is concluded that verbal cues per se or when combined with video modeling or self-video replay effectively improved single-handed shooting form, and the effects were retained after one day. However, addition of visual cues, either as video modeling or self-video replay, did not have a more advance effect on the shooting form.

\section{Implications and recommendations}

This study revealed that verbal cueing alone can enhance the learning of single-handed shooting form in the young inexperienced Hong Kong female basketball players with immediate and retention effects. Yet, it only provided an immediate benefit on the shooting accuracy but not the retention effect. With the aid of video, either as modeling or self-video replay, subjects performed more accurate and had better shooting form than those who received verbal cues only. The effects for both feedback strategies were similar.

Based on the results of this study, some implications are proposed for coaches in teaching free throw shooting techniques to young learners. First of all, the use of verbal cues is important that it can direct a learner's attention to relevant stimuli or prompt key movement pattern elements. Using verbal cues alone already provides immediate improvements for the movement of shooting. Though, this feedback method is not enough to fully enhance the performance of the learners and to retain the skill for a longer time. Coaches may consider giving video modeling or self-video replay to learners in conjunction to verbal cues to help learners gain a better performance both in outcome accuracy and movement form. As visual feedback acts as the knowledge of results, it may provide more appropriate information than the verbal knowledge of results. Coaches can then focus more on helping the learners in detecting errors and in developing a correct shooting form which may increase the scoring accuracy (Kladopoulos \& McComas, 2001). In spite of this, no matter video modeling and self-video replay, the duration of the video presented should be long enough to help learners to gain useful information to detect their errors.

The present results cannot identify any difference in the effectiveness of video modeling and self-video replay combining with verbal cues, further research is needed by considering the learners' individual ability differences. Moreover, participants' perception of the novelty of the skill will affect the results, which has not been stringently controlled in this study. Further studies should choose a skill that is truly novel to the participants and yet easy to be recognized and learned, such as, using the nondominant hand to perform a motor skill.

In addition, the sample size of this study was small (only 6 per group) which will affect the generalisability of the results (Thomas, 1998). The study can be repeated to increase the sample size. As time is needed to consolidate the learning into a positive outcome, duration of the practice sessions should be longer (at least one month) to help enhance the performance effect in the retention test (Swinnen, 1998).

Lastly, although in this study having one shooting form rater only (the first author) avoids the inter-rater variability, the rater's subjectivity might have affected the rating. Future research can include one more trained rater when evaluating the shooting form. The inter-rater reliability needs to be established to ensure the fairness of the skill performance assessment. 


\section{References}

Al-Abood, S. A., Davids, K., \& Bennett, S. J. (2001). Specificity of task constraints and effects of visual demonstration and verbal instruction in directing learners' search during skill acquisition. Journal of Motor Behavior, 33(3), 295-305.

Amberry, T. (1996). Free Throw: 7 Steps to Success at the Free Throw Line. New York: Harper Perennial.

Anshel, M. H., \& Singer, R. N. (1980). Effect of learner strategies with modular versus traditional instruction on motor skill learning and retention. Research Quarterly for Exercise and Sport, 51(3), 451-462.

Barney, D., \& McGaha, P. (2006). Where's the B. E. E. F.? Everyone Can Be a Shooter: Shooting Fundamentals and Activities Revisited. A Journal for Physical and Sport Educators, 19(5), 34-36.

Darden, G.., \& Shirmon, J. (2000). Revisit an "old" technology: Videotape feedback for motor skills learning and performance. Strategies, 13(4), 17-21.

Hagedorn, G., Niedlich, D., \& Schmidt, G.. J. (1996). The basketball manual. Reinbek bei Hamburg: Rowohlt.

Janelle, C. M., Barba, D. A., Frelich, S. C., Tennant, L. K., \& Caurangh, J. H. (1997). Maximizing performance feedback effectiveness through videotape replay and a self-controlled learning environment. Research Quarterly for Exercise and Sport, 68(4), 269-279.

Janelle, C. M., Champenoy, J. D., Coombes, S. A., \& Mousseau, M. B., (2003). Mechanisms of attentional cueing during observational learning to facilitate motor skill acquisition. Journal of Sports Sciences, 21(10), 825-838.

Kernodle, M. W., Johnson R., \& Arnold, D. R. (2001). Verbal instruction for correcting errors versus such instructions plus videotape replay on learning the overhand throw. Perceptual Motor Skills, 92(10), 3951.
Kladopoulos, C. N., \& McComas, J. J. (2001). The effects of form training on foul-shooting performance in members of a women's college basketball team. Journal of Applied Behavior Analysis, 34(3), 329-332.

Landin, D. (1994). The role of verbal cues in skill learning. Quest, 46(3), 299-313.

Magill, R. A. (1993). Modeling and verbal feedback influences on skill learning. International Journal of Sports Psychology, 24(4), 358-369.

Martens, R., Burwitz, L., \& Zuckerman J. (1976). Modeling effects on motor performance. Research Quarterly, 47(2), 277-291.

Morrison, C. S., \& Reeve, E. J. (1988). Effect of undergraduate major instruction on qualitative skill analysis. Journal of Human Movement Studies, 15(6), 291-297.

Newell, K. M., Morris, L. R., \& Scully, D. M. (1985). Augmented information and the acquisition of skill in physical activity. Exercise and Sport Science Reviews, 13, 235-261.

Onate, J. A., Guskiewicz, K. M., Marshall, S. W., Giuliani, C., Yu, B., \& Garrett, W. E. (2005). Instruction of jump-landing technique using videotape feedback. American Journal of Sports Medicine, 33(6), 831-842

Parson, M. L. (1998). Focus learner attention with verbal cues. Strategies, 11(3), 30-33.

Pettay, R. F., \& Dzewaltowski, D. A. (2001) The effect of modeling and self-modeling on performance and self-efficacy in a basketball free-throw task. Journal of Sports \& Science Psychology, 23(2), 40.

Pollock, B. J., \& Lee, T. D. (1992). Effects of the model's skill level on observational motor Learning. Research Quarterly for Exercise and Sport, 63(1), 25-29.

Rose, D. J., \& Christina, R. W. (2006). A multilevel approach to the study of motor control and learning $\left(2^{\text {nd }}\right.$ ed.). San Francisco, CA: Pearson/Benjamin Cummings. 
Schmidt, R. A., \& Wrisberg, C. A. (2008). Motor Learning and Performance: A situation-based approach $\left(4^{\text {th }}\right.$ ed.). Champaign, IL: Human Kinetics.

Singer, R., Flora, L., \& Abourezk, T. (1989). The effect of a five-step cognitive learning strategy on the acquisition of a complex motor task. Journal of Applied Sport Psychology, 1(2), 98-108.

Swinnen, S. P. (1998). Aged-related deficits in motor learning and differences in feedback processing during the production of a bimanual coordination pattern. Cognitive Neuropsychology, 15(5), 439-466.

Thomas, M. B. (1998). The effects of visual-verbal modeling on the form and outcome of basketball shooting in beginners. Eugene, OR: Microform publications, University of Oregon.

Tzetzis, G., Mantis, K., Zachopoulou, E., \& Kioumourtzoglou, E. (1999). The effect of modeling and verbal feedback on skill learning. Journal of Human Movement Studies, 36(3), 137-151.

Wiese-Bjornstal, D. M., \& Weiss, M. R. (1992). Modeling effects on children's form kinematics, performance outcome, and cognitive recognition of a sport skill: An integrated perspective. Research Quarterly for Exercise and Sport, 63(1), 67-75.

Wulf, G., Raupach, M., \& Pfeiffer F. (2005). Selfcontrolled observational practice enhances learning. Research Quarterly for Exercise and Sport, 76(1), 107-112.

\section{Correspondence}

Contact Person: Dr. Alberto Cruz

聯絡人：高達倫博士

Department of Creative Arts and Physical Education

The Hong Kong Institute of Education

10 Lo Ping Road, Tai Po, New Territories,

Hong Kong

香港教育學院體藝學系

香港新界大埔露屏路十號

Telephone 電話：(852) 29487847

Fax 傳真: (852) 29487848

E-mail_電郵: acruz@ied.edu.hk 